Nloma 2016, 34(1), 45-52

Revista de Psicologia, Ciències de l’Educació i de l'Esport

ISSN: $1138-3194$

Copyright @ 2016

www.revistaaloma.net

\title{
Percepció dels estudiants i del professorat del Grau d'Educació Primària de Blanquerna - Universitat Ramon Llull sobre la incorporació experimental de la flipped classroom
}

\author{
Jordi Simón, Elena-Sofia Ojando, Xavier Àvila, Miquel-Àngel Prats \& Antoni Miralpeix
} Universitat Ramon Llull

Rebut: $20-12-2015$

Acceptat: 18-3-2016

Percepció dels estudiants i del professorat del Grau d'Educació Primària de Blanquerna Universitat Ramon Llull sobre la incorporació experimental de la flipped classroom

Resum. La flipped classroom (classe inversa, en català) és un model d'ensenyament i aprenentatge que darrerament està prenent molt protagonisme en l'ensenyament superior. Per això aquest estudi pretén identificar i analitzar la percepció dels estudiants i professors universitaris sobre la incorporació de la flipped classroom en tres assignatures del Grau d'Educació Primària durant el curs 2014-2015 amb l'objectiu principal d'identificar els canvis que provoca la flipped classroom en general $i$, concretament, en les quatre dimensions del model didàctic: continguts i materials, estratègies d'ensenyament $i$ aprenentatge, gestió de l'aula i avaluació. Per obtenir les dades, s'ha administrat un qüestionari als estudiants $i$ s'ha realitzat un focus group amb els professors. Els resultats de l'estudi posen de manifest un alt grau de satisfacció tant per part dels estudiants com dels professors $i$ una percepció de canvi positiu en les quatre dimensions estudiades

Paraules clau: Classe inversa; tecnologia educativa; ensenyament superior; innovació educativa

Perception of students and faculty of the Primary Education program at Blanquerna Universitat Ramon Llull on the experimental incorporation of the Flipped Classroom

Summary. The Flipped Classroom is a teaching and learning model that has of late been receiving a lot of attention in the field of higher learning. For this reason, this study seeks to identify and analyse student and faculty perceptions on the incorporation of the Flipped Classroom into three classes within the Primary Education program during the 2014-2015 academic year, the study taking as its chief objective the identification of the changes brought about by the Flipped Classroom in general, and more specifically in terms of the four dimensions of the educational model: contents and materials, estratègies teaching and learning strategies, classroom management and assessment. In order to collect the data, a survey was administered to the students, while a focus group was conducted with professors. The results of the study indicate a high degree of satisfaction both on the part of the students and the professors and a perception of positive change in each of the four dimensions studied.

Keywords: Flipped Classroom; educational technology; higher education; innovation in education

Correspondencia

Jordi Simón

Facultat de Psicologia, Ciències de l'Educació i de l'Esport

Blanquerna

Universitat Ramon Llull

email: jordisl@blanquerna.url.edu 


\section{Introducció}

En els darrers anys, l'escola està experimentant molts canvis relacionats amb la introducció de la tecnologia en els processos d'ensenyament $i$ aprenentatge. Hem vist la incorporació de diferents eines i maquinari a les aules com ara les pissarres digitals interactives, els ordinadors portàtils per a cada alumne, les tauletes tàctils, els smartphones i, fins i tot, en algunes escoles, ja hi trobem alguna impressora 3D. El NMC Horizon Report, en la seva darrera edició per a K-12 (Johnson, Adams Becker, Estrada \& Freeman, 2015), ja apunta que les tecnologies emergents tindran un impacte significatiu en els pròxims anys en les nostres escoles.

Així, doncs, la inversió en tecnologia cada cop serà més evident i haurà d'estar enfocada no tan sols a la seva utilització, simplement, sinó que haurà d'anar d'acord amb una renovació pedagògica que permeti un canvi veritable $i$, per tant, caldrà que sigui reconeguda com un element vertebrador de la innovació educativa.

És a dir, actualment l'escola no solament assumeix el repte d'incorporar nous recursos i eines tecnològiques a les aules, sinó que també assumeix la responsabilitat d'innovar i transformar l'educació per tal d'adaptar-se a les noves formes d'aprendre i a les necessitats de les generacions que avui arriben a l'escola i que s'identifiquen amb denominacions com ara «Z Generation», «Aprenents del Tercer Mil·lenni», «Generació Google», «Net generation» $\mathrm{o}$, potser la més utilitzada, la de «Nadius Digitals» (Prensky, 2001).

Els alumnes d'avui estableixen una nova relació amb la informació, el coneixement i l'aprenentatge. D’acord amb l'estudi Connected Minds (Pedró, 2012), l'alumnat d'avui cobreix habitualment les seves necessitats informacionals amb internet i, per extensió, també les seves necessitats d'aprenentatge. Aquesta clara preferència vers el món digital dels nostres alumnes a l'hora de buscar informació, marca una tendència cap a una «transformació accelerada i profunda de les estratègies i hàbits informacionals dels estudiants que es pot traduir en una eclosió de noves maneres d'aprendre, fet que incideix directament en els nous models metodològics» (Vivancos, 2008). Models que, per altra banda, proposen accions que persegueixen l'aprenentatge significatiu dels alumnes amb el suport de les TIC.

A més a més, tal com apunta Siemens (2008) en la seva teoria del connectivisme, l'aprenentatge ha deixat de ser una activitat interna i individual per passar a ser una activitat col-lectiva i en xarxa, i planteja la necessitat de cercar noves estratègies d'aprenentatge pròpies de l'era digital tot posant l'èmfasi en la influència de la tecnologia.

Per tant, el principal repte de l'escola actual serà donar resposta a aquestes noves formes d'aprendre i de transmetre el coneixement que faciliten les TIC, la qual cosa passa per un canvi de la pràctica docent que s'orienti vers enfocaments pedagògics més profunds en els quals l'alumne sigui el centre de l'aprenentatge, l'espai de l'aula es converteixi en un espai d'intercanvi i de

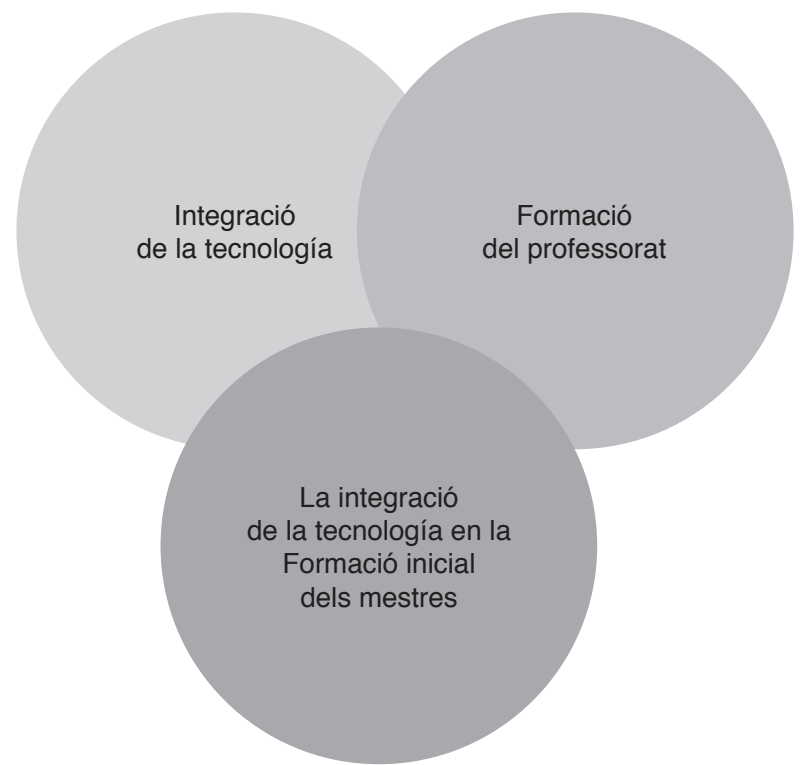

Figura 1. Relació entre els diferents elements transformadors.

col-laboració, i es potenciï el desenvolupament de les competències pròpies del segle xxI.

Davant d'aquest repte, una possible solució estaria en el binomi que formen la integració de la tecnologia a les aules, d'una banda, i la formació del professorat, de l'altra. Però, per tal d'aconseguir la veritable transformació, també hem de tenir en compte un tercer element que completa aquest binomi convertint-lo en una tríada. Es tracta de la formació inicial dels mestres, que cal reconèixer com una peça clau per a la innovació educativa a l'escola d'avui i del futur proper. Aquesta relació es pot representar com una intersecció de conjunts:

Tal com hem apuntat, repensar la pràctica docent passa també per repensar la formació inicial dels mestres i millorar la seva competència digital -davant la creixent presència d'eines digitals que tenen a la seva disposició- per donar suport als processos d'ensenyament i aprenentatge.

Tanmateix, la formació dels futurs mestres $-i$, per extensió, de tot el professorat- ha de focalitzar-se sobretot en l'adquisició de noves metodologies que s'adaptin a aquestes noves necessitats educatives i que integrin la tecnologia, però no solament promovent-ne un domini competencial de caire instrumental, sinó també aplicant models que els permetin aprofitar al màxim el potencial d'aquestes eines i adaptar-se a les necessitats dels nous estudiants.

Per tot això, i d'acord amb NMC Horizon Report (2015) en la seva edició d'ensenyament superior, la flipped classroom creiem que pot ser un bon model que permeti incorporar la tecnologia a la Universitat de manera invisible i que produeixi canvis en els processos d'ensenyament i aprenentatge.

En aquest article es presenten els resultats d'una experiència d'aplicació de la flipped classroom en l'ensenyament superior, concretament en els graus d'educació de la Facultat de Psicologia, Ciències de l'Educació i l’Esport Blanquerna de la Universitat Ramon Llull. 


\section{La flipped classroom}

La flipped classroom («classe inversa» en català) sorgeix l'any 2007 sota el guiatge de dos professors innovadors, Jonathan Bergmann i Aaron Sams, de l'institut Woodland Park de Colorado (EUA), i a partir d'aquí s'ha anat estenent a tots els nivells educatius (Tourón, Santiago, \& Diez, 2014). La flipped classroom -també anomenada classe inversa- ve a proposar, tal com el seu nom suggereix, capgirar l'escola i, més concretament, l'activitat que es fa a l'aula.

Bishop i Verleger (2013) descriuen la flipped classroom com un «nou model pedagògic» que planteja un treball fora de l'aula, per part de l'estudiant, a través de vídeos sobre la teoria i la posada en pràctica d'aquesta teoria, en un ambient de grup col-laboratiu i actiu dins l'aula, utilitzant metodologies actives com podria ser l'aprenentatge basat en problemes.

Es pot afirmar que aquest model trenca amb el model tradicional, de caire més aviat transmissor, en desplaçar, fora de l'aula, el temps que habitualment el professor utilitzava a la classe per explicar la teoria i ho fa a través de vídeos on s'exposa aquesta teoria. Aquests vídeos poden ser o bé seleccionats o bé creats pel professor i acompanyats d'una guia de treball autònom que els permeti la comprensió d'aquesta teoria exposada. D'altra banda, el temps a l'aula s'utilitzarà sobretot per a treballar habilitats de pensament d'ordre superior segons la classificació que es proposa en la Taxonomia de Bloom per a l'era digital (Churches, 2009), com ara l'anàlisi, l'avaluació i la creació a través de diferents metodologies, en un ambient d'aprenentatge col-laboratiu i amb el suport i l'acompanyament del professor.

Per tant, amb la classe inversa, el temps que tradicionalment s'utilitzava a l'aula per explicar continguts i apropar els alumnes a les idees fonamentals de cada unitat didàctica, per una banda, i a la realització d'activitats d'aplicació fora de l'aula, per l'altra, ara és just el contrari: fora de l'aula els alumnes accedeixen a la informació i als continguts facilitats pel professor i, a l'aula, és on es desenvolupen les activitats i les tasques des d'una perspectiva de treball col-laboratiu. Per tant, la classe inversa s'entén, amb l'ús de la tecnologia, com el mitjà per a arribar a l'aprenentatge i no sols com l'objecte d'aprenentatge en si mateix. Utilitza la tecnologia, per una banda, per a poder facilitar el material, les eines i els recursos necessaris per a l'aprenentatge $i$, per l'altra, , per conèixer les necessitats de l'alumne $i$, així, centrar-se veritablement en les diferents maneres d'aprendre (Bergmann \& Sams, 2012).

D'aquesta manera, els docents tenen més temps a l'aula per a treballar amb els seus alumnes i conèixer millor les seves necessitats i competències i, així, adaptar millor la seva tasca -d'una forma més personalitzada- a les maneres d'aprendre dels seus alumnes. D'altra banda, els alumnes, a l'aula, tenen l'oportunitat de fer preguntes i resoldre els problemes, amb el guiatge dels seus professors i l'ajut dels seus companys, dins d'un ambient de treball col-laboratiu. El professor esdevé un guia, un facilitador, que fa que els alumnes progressin i que ajuda a crear un ambient d'aprenentatge en el qual ell mateix, com a docent, també aprèn dels estudiants. Una bona síntesi d'aquesta idea la trobem en l'expressió de Marc Prensky: «tots som alhora alumnes i professors» (Prensky, 2011, p. 77).

Per tant, la flipped classroom és un model d'ensenyament $\mathrm{i}$ aprenentatge que consisteix, en certa manera, a invertir el rol del professor i el de l'alumne, tant dins com fora de l'aula, tot integrant de manera invisible l'ús de la tecnologia.

Tanmateix, la implementació d'aquests nous models i estratègies ha d'anar acompanyada, necessàriament, de recerques que contribueixin en la millora de la qualitat de l'aprenentatge perseguint la innovació pedagògica.

És en aquest punt on es situa el nostre Projecte d’Incorporació de la Classe Inversa (en endavant PICI).

\section{El Projecte d'Incorporació de la Classe Inversa (PICI)}

L'Agència de Gestió d'Ajuts Universitaris i de Recerca (AGAUR) va obrir una convocatòria per impulsar ajuts de recerca en millora i innovació en la formació inicial de mestres per a les titulacions impartides a les universitats participants en el Programa de Millora i Innovació en la Formació de Mestres (ARMIF 2014), en la qual es va presentar aquest Projecte d'Incorporació de la Classe Inversa (http://classeinversa.cat).

PICI va néixer amb la finalitat d'implementar i avaluar simultàniament el model de flipped classroom en l'etapa d’Educació Primària i en el Grau d'Educació Primària de la Universitat, com també amb la de crear sinergies entre l'escola i la Universitat sota el propòsit d'incorporar el mateix model d'ensenyament i aprenentatge. Per a garantir una transferència de coneixement autèntica entre la formació inicial i la pràctica real a les escoles, es considera bàsic compartir estratègies i metodologies didàctiques entre l'etapa d'Educació Primària i la pròpia formació universitària dels futurs mestres del segle XxI.

En aquest context va semblar oportú, doncs, comprovar en quina mesura un nou model com el de la classe inversa promou la implementació de processos d'aprenentatge innovadors relacionats, en aquest cas, amb el canvi de rol del professor, el qual, tal com s'ha apuntat, haurà esdevenir un guia que impulsi el treball col-laboratiu i l'aprenentatge entre iguals, que promogui un aprenentatge més personalitzat i que potenciï el treball per competències, la integració de les tecnologies digitals i l'avaluació formativa.

Aquest article fa referència a la primera fase d'avaluació del projecte PICI (estiu 2015) i té per finalitat analitzar i avaluar l'impacte de la classe inversa com a model d'innovació educativa segons diverses dimensions d'anàlisi, com ara estratègies d'ensenyament, estratègies d'aprenentatge, continguts i competències, gestió de l'aula i avaluació, tot identificant els canvis percebuts pels estudiants i els professors del Grau d'Educació Primària de la Facultat de Psicologia, Cièn- 
cies de l'Educació i de l’Esport Blanquerna (Universitat Ramon Llull) en la implementació d'aquest model.

\section{Metodologia}

La metodologia de treball del projecte PICI està basada en la investigació-acció (Latorre, 2008), de manera que els mateixos investigadors són els que realitzen les experiències, reflexionen i les avaluen per tal d'aplicar les conclusions extretes a la pròpia pràctica posterior (Quintanal \& García, 2012). Aquesta proposta de treball ens apropa també al concepte de pràctica reflexiva (Dewey, 1995).

Concretament, aquesta dinàmica de treball es basa en l'esquema cíclic del model d'investigació-acció de Whitehead (Latorre, 2008), que té les fases següents:

1. Identificar un problema

2. Imaginar la solució del problema

3. Posar en pràctica la solució imaginada

4. Avaluar els resultats de les accions implementades

5. Modificar la pràctica en base als resultats

L'equip d'investigadors participants està format per un grup heterogeni de professors que combina mestres en actiu de tres escoles d'Educació Primària de la ciutat de Barcelona (l'escola pública Collaso i Gil, i les escoles privades concertades Virolai i Jesuïtes Gràcia) i professors del grau de Primària de la Facultat de Psicologia, Ciències de l’Educació i l’Esport Blanquerna de la Universitat Ramon Llull.

La primera fase es va realitzar entre el març i el maig de 2014. En aquest període es va definir el projecte i es van programar dues fases d'implementació i avaluació de la classe inversa de manera que es pogués modificar i tornar a avaluar la pràctica educativa. Així, al llarg del curs 2104-2015 es va dur a terme la primera implementació de la classe inversa i es va avaluar l'estiu de 2015.

Tal com s'ha dit abans, les dades que es mostren en aquest article fan referència exclusivament a la primera fase d'implementació a la Universitat. És a dir, són dades recollides els mesos de juny i juliol de l'any 2015. Part de l'experiència realitzada a Primària i els seus resultats es pot consultar en diferents publicacions (Simon, De Britos \& Ojando, 2015; Simon, Ojando, Avila, Prats, Gonzalez, \& Miralpeix, 2015)

Els instruments utilitzats en la recerca han estat dos: un qüestionari administrat als estudiants del grau d’Educació Primària que van participar en la recerca -aquest qüestionari parteix del dissenyat per Driscoll (2012) i està adaptat ad hoc per a aquest estudi- i un focus group en el qual van participar els professors que havien impartit les matèries que es van invertir.

Tant el qüestionari com el focus group es van estructurar per recollir informació sobre les quatre dimensions esmentades:

1. Canvis en el model didàctic en relació als continguts i als materials de classe utilitzats.

2. Canvis en el model didàctic en relació a les estratègies d'ensenyament i aprenentatge.

3. Canvis en el model didàctic en relació a la gestió de l'aula.
Taula 1. Coneixements previs sobre la flipped classroom

\begin{tabular}{lll}
\hline Preguntes & Sí & No \\
\hline $\begin{array}{l}\text { Havies sentit a parlar mai de la flipped } \\
\text { classroom? }\end{array}$ & $8(18.6 \%)$ & $35(81.4 \%)$ \\
$\begin{array}{l}\text { Havies experimentat mai una classe amb } \\
\text { la flipped classroom? }\end{array}$ & $3(9.3 \%)$ & $40(90.7 \%)$
\end{tabular}

4. Canvis en el model didàctic en relació a l'avaluació.

El qüestionari constava d'uns ítems d'identificació inicials referents a l'edat, el gènere, l'assignatura... per concretar la mostra; després hi havia dues preguntes relacionades amb la utilització prèvia de la flipped classroom i la resta del qüestionari eren 33 preguntes que giraven a l'entorn de les dimensions analitzades.

Aquest qüestionari es va administrar en línia, utilitzant l'eina Google Forms, i se n'havia fet prèviament una prova pilot amb estudiants a inicis del curs 20142015, que va permetre adaptar alguns ítems segons les categories i millorar-ne el redactat per facilitar-ne la comprensió.

La mostra d'estudiants va ser de $43(\mathrm{~N}=43)$ d'un rang d'edat entre 21 i 43 anys (mitja $=24.1)$, dels quals 12 eren homes i 31 dones.

Els estudiants de la mostra, en un alt percentatge, no havien sentit a parlar mai de la flipped classroom i tampoc no havien experimentat aquesta metodologia, tal com veiem reflectit en la taula 1 .

Els estudiants que manifestaren que havien sentit a parlar de la flipped classroom expliciten que havia estat en alguna assignatura de Tecnologies de la Informació i la Comunicació (d'ara endavant TIC) realitzada altres anys o en el seu procés de cerca de noves metodologies o a fora de la Universitat.

Les matèries del grau d'Educació Primària que van cursar al llarg del curs 2014-2015 van ser aquestes: Usos de les TIC a l'educació, Educació Musical i la seva didàctica, i Disseny de materials en entorns digitals.

El focus group amb professors es va implementar el mes de juliol de 2015 i hi van participar els professors que havien impartit les matèries que es van invertir durant aquell curs. Aquesta tècnica es va estructurar, igual que el qüestionari, seguint les quatre dimensions esmentades.

En resum, el qüestionari aporta informació sobre la percepció de l'estudiant, mentre que el focus group se centra en la perspectiva del professorat.

\section{Resultats i discussió}

Els resultats estan agrupats en les quatre dimensions descrites en l'apartat anterior i a continuació hi ha un apartat on es recullen les valoracions globals d'estudiants i professors.

Els resultats relatius a la dimensió Canvis en el model didàctic en relació als continguts i als materials de classe utilitzats (taula 2) revelen que tots els ítems tenen una alta valoració que oscil-la entre «bastant» $\mathbf{i}$ «molt».

Cal assenyalar que els estudiants destaquen que «s'han utilitzat materials didàctics en formats diferents» $($ molt $=74.4 \%)$. 
Taula 2. Ítems sobre els canvis en el model didàctic en relació als continguts i als materials de classe utilitzats

\begin{tabular}{|c|c|c|c|c|}
\hline Ítems & Gens & Poc & Bastant & Molt \\
\hline 1. Els materials i recursos didàctics són de fàcil accés. & $0(0 \%)$ & $1(2.3 \%)$ & $24(55.8 \%)$ & $18(41.9 \%)$ \\
\hline 2. S'utilitzen diferents recursos i materials. & $0(0 \%)$ & $2(4.7 \%)$ & $16(37.2 \%)$ & $25(58.1 \%)$ \\
\hline 4. Els alumnes creen material didàctic. & $0(0 \%)$ & $6(14 \%)$ & $24(55.8 \%)$ & $13(30.2 \%)$ \\
\hline 5. Els materials s'adapten a tot tipus de nivells d'aprenentatge. & $0(0 \%)$ & $5(11.6 \%)$ & $21(48.8 \%)$ & $17(39.5 \%)$ \\
\hline 7. Els materials i recursos ajuden a seguir millor el meu ritme d'aprenentatge. & $0(0 \%)$ & $3(7 \%)$ & $23(53.5 \%)$ & $17(39.5 \%)$ \\
\hline 8. Els material i els recursos ajuden a aprendre més. & $0(0 \%)$ & $4(9.3 \%)$ & $22(51.2 \%)$ & $17(39.5 \%)$ \\
\hline 9. Quan utilitzo els materials, aquests em van donant pautes del meu progrés. & $0(0 \%)$ & $11(33.3 \%)$ & $15(45.5 \%)$ & $7(21.2 \%)$ \\
\hline
\end{tabular}

L'ítem d'aquesta dimensió que ha donat un resultat més baix és el que fa referència a les pautes que es donen als estudiants en el moment del treball autònom, que consideren que són insuficients.

I, per altra banda, destaca la valoració positiva que es fa de l'accés als materials digitals, d'acord amb el que descriuen Bishop i Verleger (2013).

La informació que s'extreu de les dades del focus group realitzat amb professors és diferent i complementària de la que s'extreu de les dades obtingudes amb els qüestionaris passats als estudiants. Els professors posen l'accent en el temps que cal per crear el material; creuen que les possibilitats que avui en dia ofereix la xarxa són realment immenses; defensen la necessitat de tractar els estudiants com a futurs mestres i proposen que siguin ells els qui creïn el material; afirmen que el material sempre ha d'estar en procés de revisió i coincideixen en el fet que actualment els estudiants utilitzen aplicacions per a dispositius mòbils.

Pel que fa a la informació dels estudiants, en aquest apartat posen de manifest la seva preferència pel món digital, tant a l'hora d'aprendre com també a l'hora de crear i dissenyar material didàctic, fet que incideix directament en els nous models metodològics, tal com apunta Vivancos (2008).

Els resultats que fan referència a la dimensió Canvis en el model didàctic en relació a les estratègies d'ensenyament $\mathrm{i}$ aprenentatge mostren també un alt índex d'acceptació per part dels estudiants (Taula 3). Cal destacar que els docents tenen la percepció que els alumnes, quan utilitzen la flipped classroom, tenen un rol més actiu i el seu aprenentatge és més experiencial. En aquest sentit, tal com destaquen Bergmann i Sams (2012), els docents tenen més temps a l'aula per a treballar amb els seus alumnes i conèixer millor les seves necessitats i competències per tal d'adaptar-se millor i d'una manera més personalitzada a les seves formes d'aprendre. Per la seva part, els alumnes tenen l'oportunitat de fer preguntes i resoldre els problemes amb el guiatge dels seus professors i amb l'ajut dels seus companys dins d'un ambient de treball collaboratiu. El professor esdevé un guia, un facilitador, per tal que els alumnes progressin i es crea un ambient d'aprenentatge en què el docent també aprèn amb els estudiants.

Els professors, en el focus group, tot i que la valoració fou globalment positiva, van destacar una sèrie d'elements que caldria millorar i que feien referència a la necessitat d'un canvi de mentalitat per part dels estudiants, ja que aquests han de treballar necessàriament abans de la sessió de classe i això requereix un esforç extra per part seva. A més, constaten que «el fet de tenir material en el web no vol dir que funcioni per al treball autònom», destacant que calen accions destinades específicament a motivar o a incentivar els estudiants per tal que treballin abans d'assistir a classe.

Per exemple, un professor va expressar el següent: «En certes matèries és molt interessant, però en d'altres falten dosis extres de motivació. És dur per a l'estudiant posar-se a fer feina pel seu compte».

D’altra banda també és reveladora la frase «...quan arriben a classe ja han treballat la matèria, [...] l'aprenentatge és molt més profitós. Abans es perdia temps en la transmissió de continguts», que ve a resumir en bona part la filosofia inherent al model flipped classroom, tal com apunten Bishop i Verleger (2013).

Per acabar, cal destacar la necessitat expressada pels professors de disposar, tant per a ells mateixos com

Taula 3. Ítems sobre els canvis en el model didàctic en relació a les estratègies d'ensenyament i aprenentatge

\begin{tabular}{|c|c|c|c|c|}
\hline Ítems & Gens & Poc & Bastant & Molt \\
\hline 10. El professor passa a ser un guia de l'aprenentatge de l'alumne. & $0(0 \%)$ & $2(4.7 \%)$ & $15(34.9 \%)$ & $26(60.5 \%)$ \\
\hline 11. L'alumne adquireix un rol actiu durant el procés d'aprenentatge. & $0(0 \%)$ & $1(2.3 \%)$ & $9(20.9 \%)$ & $33(76.7 \%)$ \\
\hline 13. L'aprenentatge és més actiu i experiencial. & $0(0 \%)$ & $1(2.3 \%)$ & $13(30.2 \%)$ & $29(67.4 \%)$ \\
\hline 14. Es fomenta el treball col-laboratiu. & $0(0 \%)$ & $3(7 \%)$ & $17(39.5 \%)$ & $23(53.5 \%)$ \\
\hline 16. S'adquireix un aprenentatge més significatiu. & $0(0 \%)$ & $1(2.3 \%)$ & $19(44.2 \%)$ & $23(53.5 \%)$ \\
\hline 17. L'alumne adquireix habilitats de treball autònom. & $0(0 \%)$ & $0(0 \%)$ & $15(45.5 \%)$ & $18(54.5 \%)$ \\
\hline 18. Amb la flipped classroom tinc més ganes de continuar aprenent. & $0(0 \%)$ & $3(9.1 \%)$ & $16(48.5 \%)$ & $14(42.4 \%)$ \\
\hline
\end{tabular}


Taula 4. Ítems sobre els canvis en el model didàctic en relació a la gestió de l'aula

\begin{tabular}{|c|c|c|c|c|}
\hline Ítems & Gens & Poc & Bastant & Molt \\
\hline 19. La flipped classroom permet conèixer millor les capacitats dels estudiants. & $1(2.3 \%)$ & $4(9.3 \%)$ & $30(69.8 \%)$ & $8(18.6 \%)$ \\
\hline 20. La flipped classroom permet conèixer millor les necessitats dels estudiants. & $0(0 \%)$ & $8(18.6 \%)$ & $21(48.8 \%)$ & $14(32.6 \%)$ \\
\hline 22. La flipped classroom permet plantejar activitats més interactives. & $0(0 \%)$ & $1(2.3 \%)$ & $11(25.6 \%)$ & $31(72.1 \%)$ \\
\hline 23. La gestió dels temps és adequada als diferents ritmes d'aprenentatge. & $1(2.3 \%)$ & $3(7 \%)$ & $25(58.1 \%)$ & $14(32.6 \%)$ \\
\hline 25. S'interacciona més amb el professor/a fora de l'aula. & $0(0 \%)$ & $11(25.6 \%)$ & $19(44.2 \%)$ & $13(30.2 \%)$ \\
\hline 26. S'interacciona més amb els companys/es a l'aula. & $0(0 \%)$ & $4(9.3 \%)$ & $12(27.9 \%)$ & $27(62.8 \%)$ \\
\hline 27. S'interacciona més amb els companys/es fora de l'aula. & $1(2.3 \%)$ & $11(25.6 \%)$ & $15(34.9 \%)$ & $16(37.2 \%)$ \\
\hline
\end{tabular}

també per als estudiants, $d^{\prime}$ «indicadors del progrés del treball autònom».

Veiem, doncs, com els professors posen més èmfasi en les estratègies d'aprenentatge, es preocupen sobretot pel seguiment del treball autònom de l'estudiant i posen de manifest la necessitat de gestionar el canvi en les estratègies dels alumnes. D’altra banda, són els estudiants els qui destaquen més positivament el seu rol actiu, tant a l'aula com a fora de l'aula, i valoren positivament de manera unànime l'adquisició d'habilitats per al treball autònom.

La taula 4 mostra els resultats relatius a la dimensió Canvis en el model didàctic en relació a la gestió de l'aula $i$, seguint la mateixa tendència observada en les dues dimensions anteriors, es pot dir que reflecteix unes dades que en tots els ítems se situen entre «bastant» $\mathbf{i}$ «molt», la qual cosa indica que els estudiants observen canvis en relació a la gestió de l'aula quan es treballa en el format de flipped classroom. D'entre totes les dades es pot destacar que els estudiants valoren que en aquest model hi ha més interacció amb els companys dins l'aula i que les activitats a classe són més interactives.

Però, per altra banda, els estudiants apunten que cal millorar les interaccions entre les parts fora de l'aula, ja que indiquen que no augmenten en la mateixa proporció que en la resta d'ítems. Un 25.6 \% dels estudiants indiquen «poc» en els dos ítems que fan referència a aquest aspecte, la qual cosa, en relació amb la puntuació de la resta d'ítems de l'estudi, es pot considerar que és baixa.

Les aportacions dels professors en relació a aquesta dimensió no afegeixen informació significativament diferent a la dels estudiants, ja que en els focus groups $s$ 'hi fa poca referència. Un dels professors opina que «els alumnes fan aportacions més interessants i pots fer millor seguiment»; un altre destaca que «els estudiants ampliaven per si sols la informació donada» i, per últim, hi ha consens en el fet que «les tasques a classe són més riques».

Els resultats referents a la dimensió Canvis en el model didàctic en relació a l'avaluació, que es mostren en la taula 5, ens indiquen que els estudiants tenen una percepció positiva general sobre això, sense destacar cap ítem per sobre dels altres.

Per altra banda, les aportacions dels professors són molt diverses; podem esmentar les següents:

Un professor destaca el portafoli com una eina que ha funcionat en la implementació del model de flipped classroom: «el portafoli (dossier personal d'aprenentatge) ha funcionat molt bé per a avaluar i per a autoavaluar-se». Aquesta afirmació inclou dos ítems importants com són l'avaluació i l'autoavaluació en un mateix instrument.

Entre els professors, hi ha opinions confrontades respecte al moment en què els estudiants s'avaluen. Per exemple, hi ha qui opina que aquests «s'avaluen a classe, no abans» i d'altres que els estudiants utilitzen «qüestionaris autocorrectius o Kahoot abans de la discussió».

Un altre exemple de visions contraposades el trobem en relació amb el seguiment de l'estudiant, quan un professor destaca que, en el model de flipped classroom, «es té més informació del procés (d'aprenentatge de l'estudiant)», mentre que un altre apunta, en sentit contrari, que «hi ha dificultat de retorn/seguiment del treball autònom (de l'estudiant)».

Per finalitzar, en aquest aspecte també cal esmentar que un dels professors reconeix que «l'avaluació s'hauria de millorar; no hem indagat en tipologies d'avaluació».

Aquesta última valoració coincideix també amb la percepció dels estudiants, ja que no es detecta que hi

Taula 5. Ítems sobre els canvis en el model didàctic en relació a l'avaluació

\begin{tabular}{|c|c|c|c|c|}
\hline Ítems & Gens & Poc & Bastant & Molt \\
\hline 28. L’avaluació és contínua. & $0(0 \%)$ & $2(4.7 \%)$ & $16(37.2 \%)$ & $25(58.1 \%)$ \\
\hline 29. S'avaluen les competències dels alumnes. & $0(0 \%)$ & $1(2.3 \%)$ & $23(53.5 \%)$ & $19(44.2 \%)$ \\
\hline 31. S'utilitzen diferents sistemes d'avaluació (més enllà de l'examen). & $0(0 \%)$ & $0(0 \%)$ & $16(37.2 \%)$ & $27(62.8 \%)$ \\
\hline 32. S’utilitza la coavaluació. & $0(0 \%)$ & $1(2.3 \%)$ & $17(39.5 \%)$ & $25(58.1 \%)$ \\
\hline
\end{tabular}


Taula 6. Comparació entre les quatre dimensions d'estudi

\begin{tabular}{ll}
\hline Dimensió & $\mathrm{X}$ \\
\hline Continguts i materials utilitzats & 3.31 \\
Estratègies d'ensenyament i aprenentatge & 3.41 \\
Gestió de l'aula & 3.24 \\
Avaluació & 3.53 \\
Mitjana & 3.37 \\
\hline
\end{tabular}

hagi una majoria que estiguin satisfets amb la utilització de diferents sistemes d'avaluació, com, per exemple, la coavaluació o l'autoavaluació, tal com es pot veure en la taula 5.

Resultats referents a la valoració final dels estudiants i els professors sobre el model de flipped classroom

Hi ha diferents dades en l'estudi que permeten aproximar-nos a la valoració global de l'experiència. En primer lloc s'ha optat per tractar els resultats del qüestionari passat als estudiants agrupant-los en les diferents dimensions de l'estudi, com si fossin escales, la qual cosa ha permès fer-ne una comparació representada en la taula 6.

Per poder tractar les dimensions com si fossin una escala, s'ha adjudicat als diferents ítems un valor en un rang entre 1 i 4, i a partir d'aquí se n'han calculat les puntuacions mitjanes. Això comporta certes limitacions metodològiques, ja que a cada ítem se li ha adjudicat el mateix pes en l'escala segons un criteri simplement aritmètic.

Malgrat aquestes limitacions, podem extreure una primera valoració global i és que el resultat final en les quatre dimensions estudiades és d'una magnitud similar.

Hi ha una preocupació pel que fa a la promoció i gestió del treball autònom. A partir dels resultats es planteja la necessitat de resoldre alguns uns interrogants, com, per exemple, aquests: Quins hàbits de treball autònom tenen els estudiants? De quins suports disposa l'estudiant per al seu treball autònom? El material que s'utilitza, s'adapta prou al nivell de coneixements previ de cada estudiant? Com es pot avaluar la feina feta autònomament?... En aquesta línia, tant els estudiants com els professors fan referència, en diferents moments, a la necessitat que l'estudiant ha de «canviar el xip» i s'ha de potenciar el treball previ a les classes.

En general, els professors són més crítics que els estudiants en el moment d'explicitar les seves percepcions, la qual cosa potser té relació amb el rol diferent que exerceixen els uns i els altres o, potser, és un indicador del fet que els estudiants se senten millor que els professors amb aquest nou model, ja que els és més propi per qüestions generacionals.

Els estudiants d'educació veuen el model de flipped classroom com un bon model a aplicar en la seva futura pràctica docent.

Als professors, a diferència dels estudiants, els preocupa l'avaluació del model de flipped classroom
Taula 7. A partir d'ara, faries servir la flipped classrom, com a futur mestre, en les teves classes?

\begin{tabular}{ll}
\hline Resposta & N (\%) \\
\hline Sí & $29(67,4 \%)$ \\
Sí amb matisacions & $12(27,9 \%)$ \\
No & $2(4,7 \%)$ \\
\hline
\end{tabular}

En definitiva, la percepció tant dels estudiants com dels professors és que la flipped classroom aproxima l'aprenentatge a la vida real actual, que en gran part és digital pel que fa a l'accés al coneixement, a la comunicació i a l'ús de les eines i recursos tecnològics. Atorga més autonomia i centra el protagonisme en l'estudiant i potencia el treball col-laboratiu, tal com ja propugnaven els models de l'escola activa. Actualment, amb la tecnologia aliada de la pedagogia, és possible concretar, en la pràctica, aquests ideals educatius. La filosofia de la flipped classroom, en molts casos, ja no és solament una possibilitat, sinó que, en un context sociodigital com l'actual, esdevé una necessitat, tal com apunta l'Informe Horizon en la seva edició d'ensenyament superior (2015).

Val a dir que les limitacions d'aquest estudi se centren principalment en la metodologia emprada, ja que el mateix model d'investigació-acció sol reflectir prioritàriament el punt de vista dels participants (Neira, 2005), que són, a la vegada, els propis investigadors i això genera certes friccions amb alguns dels principis de la recerca científica com, per exemple, la neutralitat. Així, doncs, caldrà considerar les conclusions d'aquest article des d'aquesta perspectiva.

Per altra banda, tenint en compte que es presenta una part d'un projecte de recerca dissenyat amb una durada de dos cursos, les aportacions d'aquest article també s'han de considerar com una mirada en un punt d'un camí inacabat, tal com s'ha apuntat anteriorment. El pas següent serà recollir les dades corresponents a l'experiència d'incoporació de la flipped classroom del curs 2015-2016, fer una nova anàlisi de les mateixes dimensions i comparar els resultats amb els que aquí s'han exposat, amb la qual cosa es completarà el cicle de la investigació-acció duta a terme.

\section{Referències}

Bergmann, J., \& Sams, A. (2012). Flip your classroom: reach every student in every class every day. Eugene, OR.; Alexandria, VA.: ISTE ; ASCD.

Bishop, J. L., \& Verleger, M. A. (2013, June). The Flipped Classroom: A survey of the research. In ASEE National Conference Proceedings, Atlanta, GA.

Churches, A. (2009). Bloom's digital taxonomy. Retrieved October, 30, 2012.

Dewey, J (1995). Democracia y educación. Madrid: Ed. Morata.

Driscoll, T. (2012). Flipped learning and democratic education: The complete report.

Johnson, L., Adams Becker, S., Estrada, V., \& Freeman, A. (2015). NMC Horizon Report: 2015 K-12 Edition. 
Austin, Texas: The New Media Consortium.

Johnson, L., Adams Becker, S., Estrada, V., \& Freeman, A. (2015). NMC Horizon Report: 2015 Higher Education Edition. Austin, Texas: The New Media Consortium.

Latorre, A. (2008). La investigación-acción. Conocer y cambiar la práctica educativa. Barcelona: Ed. Graó.

Neira, T. R. (2005). Fronteras y límites de la investigación-acción. Enseñanza de las ciencias sociales: Revista de investigación, 4, 93-104.

Pedró, F. (2012) Connected Minds: Technology and today's learners. París: OECD

Prensky, M. (2001). Nativos digitales, inmigrantes digitales. Retrieved from http://files.educunab.webnode. cl/200000062-5aba35bb22/Nativos-digitales-parte1. pdf

Prensky, M (2011). Enseñar a nativos digitales. UE: ediciones SM

Quintanal, J. \& García, B. (Coords.) (2012). Fundamentos básicos de metodología de investigación educativa. Barcelona: Ed. CCS.

Siemens, G. (2008) New structures and spaces of learning: The systemic impact of connective knowledge, connectivism, and networked learning. A: Actas do encontro sobre web 2.0 [en línia], Braga (Portugal) Retrieved from http://elearnspace.org/Articles/systemic_impact.htm

Simon, J., De Britos, C., \& , Ojando, E. (2015). Flip your class with the help of your students. Aula de Innovación educativa, 246, 21-25.

Simon, J., Ojando, E., Avila, X., Prats, A., Gonzalez, L., \& Miralpeix, A (2015). Project of flipped classroom's incorporation: an experience between primary schools and university. En M. Carmo (Ed.), END 2015. International conference on education and new developments (pp. 146-150). Porto, Portugal.

Tourón, J., Santiago, R., \& Diez, A. (2014). The Flipped Classroom: Cómo convertir la escuela en un espacio de aprendizaje. Grupo Océano.

Vivancos, J. (2008). Tratamiento de la información y competencia digital. Madrid: Alianza Editorial.

Percepción de los estudiantes y del professorado del Grado de Educación Primaria de Blanquerna Universitat Ramon Llull sobre la incorporación experimental de la flipped classroom

Resumen. La flipped classroom es un modelo de enseñanza y aprendizaje que últimamente está tomando mucho protagonismo en la enseñanza superior. Es por ello, que este estudio pretende identificar y analizar la percepción de los estudiantes y profesores universitarios sobre la incorporación de la flipped classroom en tres asignaturas del Grado de Educación Primaria durante el curso 2014-2015 con el objetivo principal de identificar los cambios que provoca la flipped classroom en general $y$, concretamente, en las cuatro dimensiones del modelo didáctico: contenidos y materiales, estrategias de enseñanza y aprendizaje, gestión del aula y evaluación. Para obtener los datos, se ha administrado un cuestionario a los estudiantes y se ha realizado un focus group con los profesores. Los resultados del estudio ponen de manifiesto un alto grado de satisfacción tanto por parte de los estudiantes como de los professores y una percepción de cambió positivo en las cuatro dimensiones estudiadas.

Palabras clave: Clase invertida; tecnología educativa; enseñanza superior; innovación educativa 